\title{
A Novel Modified Switched Inductor Boost Converter with Reduced Switch Voltage Stress
}

Graduate Students Science \& Engineering

\section{Shima Sadaf, Nasser Al-Emadi, Atif Iqbal, Mohammad Meraj, Mahajan Sagar Bhaskar Department of Electrical Engineering, Qatar University, Doha, Qatar s.sadaf@qu.edu.qa, alemadin@qu.edu.qa, atif.lqbal@qu.edu.qa, meraj@qu.edu.qa, sagar25.mahajan@gmail.com}

\section{Abstract}

DC-DC power converters are necessary to step-up the voltage or current with high conversion ratio for many applications e.g. photovoltaic and fuel cell energy conversion, uninterruptible power supply, DC microgrid, automobile, high intensity discharged lamp ballast, hybrid vehicle, etc. in order to use low voltage sources. In this project, a modified SIBC (mSIBC) is proposed with reduced voltage stress across active switches. The proposed mSIBC configuration is transformer-less and simply derived by replacing one diode of the classical switched inductor structure with an active switch. As a result, mSIBC required low voltage rating active switches, as the total output voltage is shared between two active switches. Moreover, the proposed mSIBC is low in cost, provides higher efficiency and required the same number of components compared to the classical SIBC. The experimental results are presented which validated the theoretical analysis and functionality, and the efficiency of the designed converter is $97.17 \%$. The newly designed configurations will aid the intermediate power stage between the renewable sources and utility grid or high voltage DC or AC load. Since, the total output voltage is distributed among the two active switches, low voltage rating switches can be employed to design the power circuit of the proposed converter. The classical boost converter or recently proposed switched inductor based boost converter can be replaced by the proposed mSIBC converter in real-time applications such as DC microgrid, DC-DC charger, battery backup system, UPS, EV, an electric utility grid. The proposed power circuitry is Cost effective, Compact in size, easily diagnostic, highly efficient and reliable.

\section{Keywords}

DC-DC Converter, High Voltage Conversion Ratio, Switched Inductor Boost (SI-B) converter, Transformer-less, Voltage stress reduction

\section{Comparison of Converters}
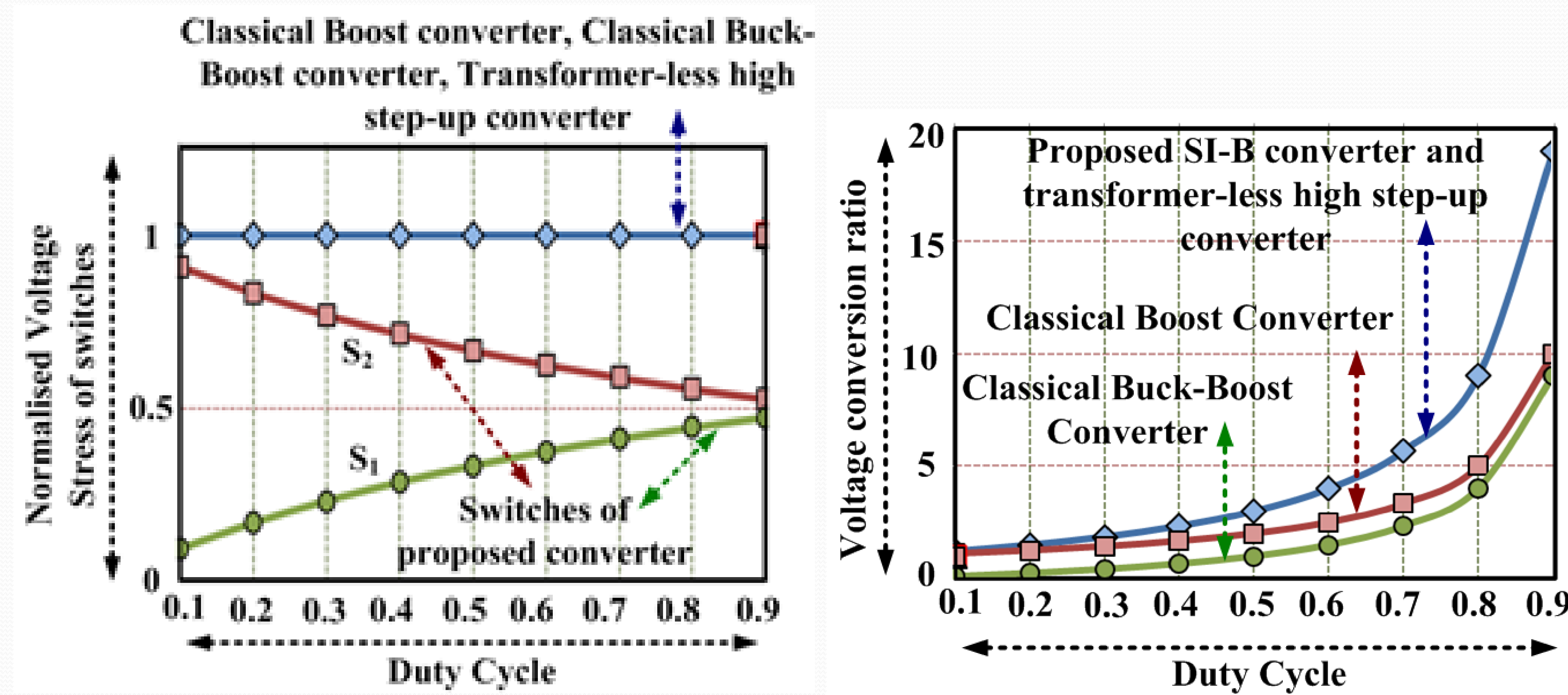

Acknowledgement

This publication was made possible by Qatar University High Impact grant \# [QUHI-CENG-19/20-2]

\section{Proposed Converter Circuit}

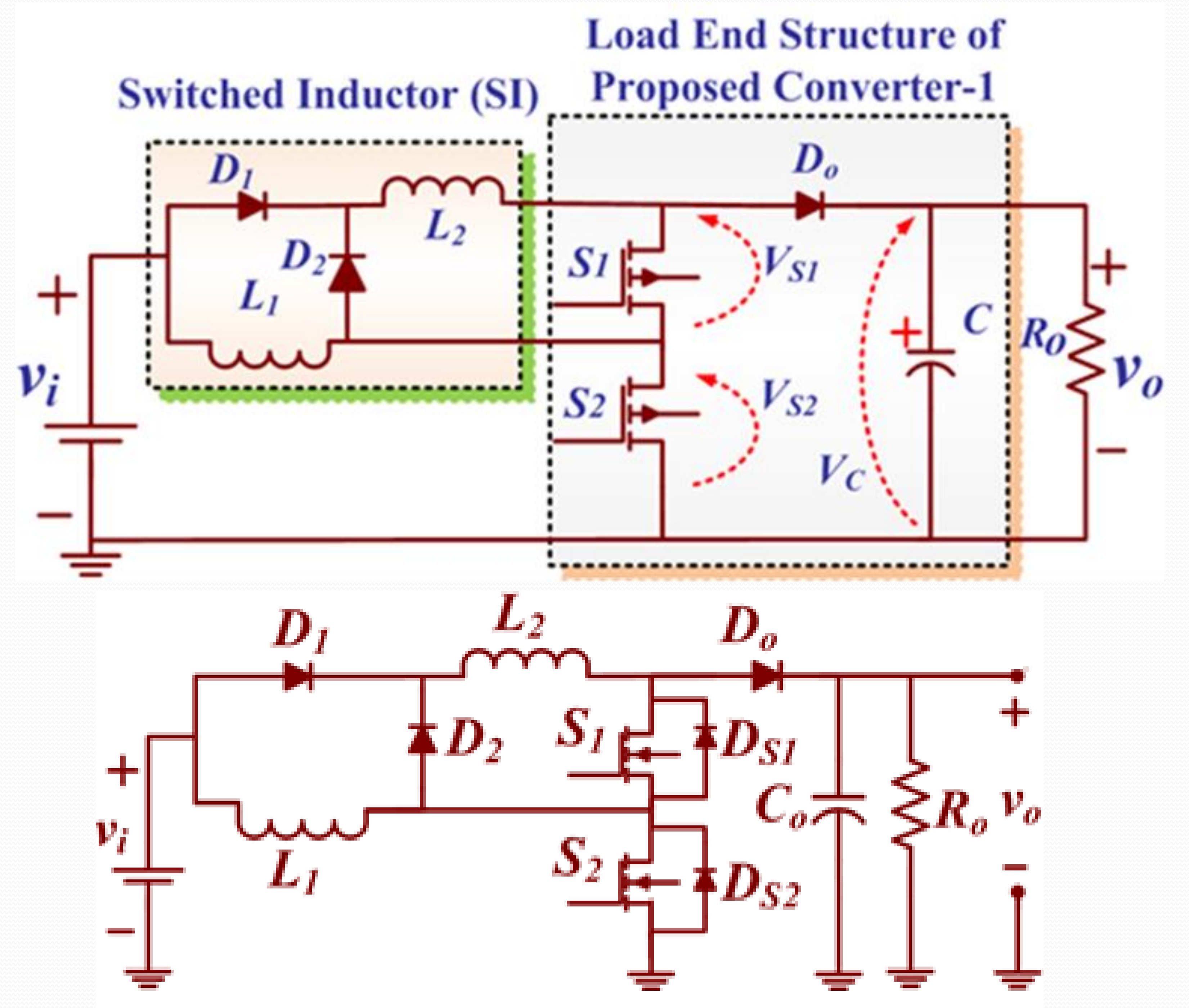

Experimental Test Plots
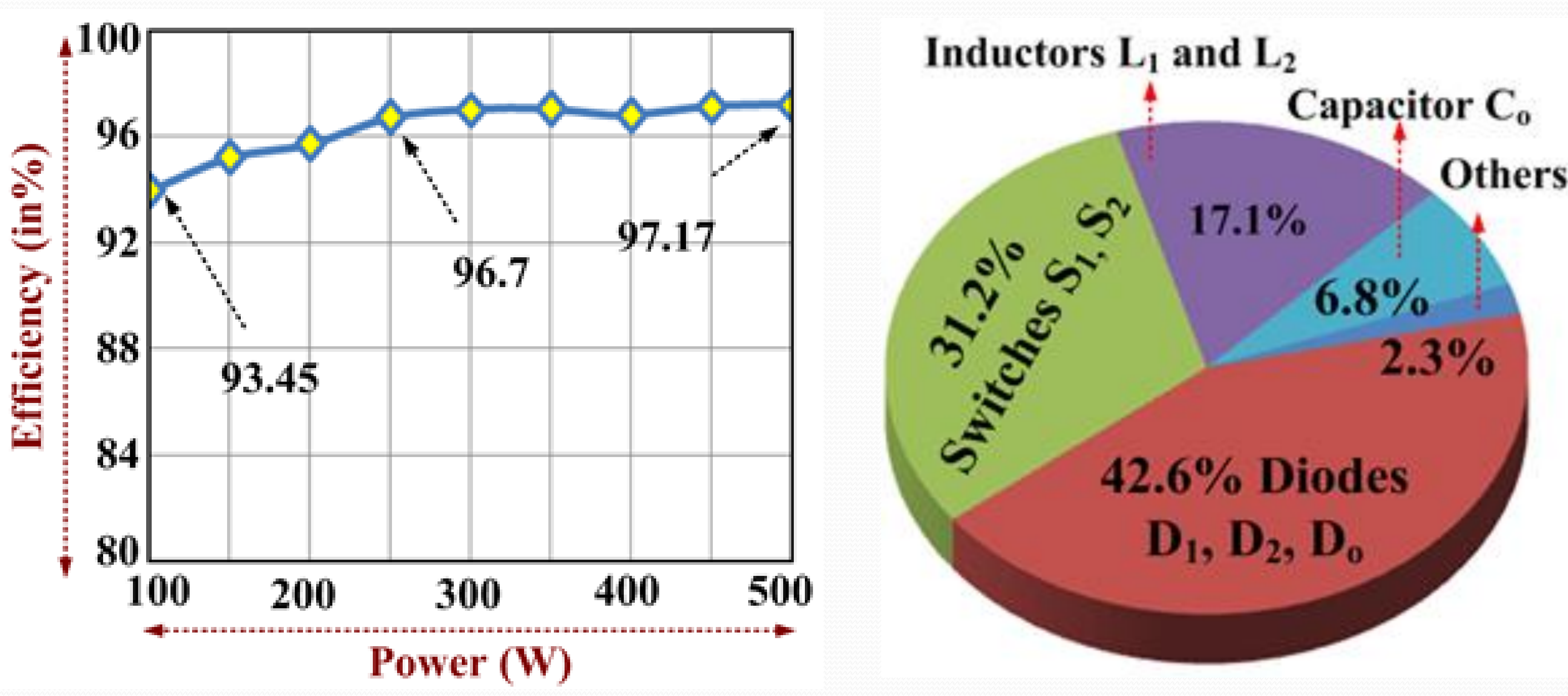

(a) Efficiency versus power, (b) Loss distribution at 500W.

\section{Applications}

- For feeding auxiliary loads, or to control the speed of electric DC drives that can be used, and for low to required voltage level conversion in Electric and hybrid electric vehicles

- In stages of modular multilevel converter for extra high voltage DC generation, high voltage Electric Vehicle or train, DC Home, High voltage automotive applications, military applications, Telecom applications

- Advanced distribution networks: voltage control, reactive power control, Smart grid, Wireless power transfer

- Home energy distribution, Islanded microgrid- ship, boats, desert, passenger plane, DC distribution : 2 wire-3level voltage

- Robotic applications, Avionics applications, Advanced high power line high frequency drive application.

\section{Publications}

1. S. Sadaf, S. B. Mahajan, M. Meraj, A. Iqbal and N. Alemadi, "A Novel Modified Switched Inductor Boost Converter with Reduced Switch Voltage Stress," in IEEE Transactions on Industrial Electronics.

2. S. Sadaf, N. A. Al-Emadi, A. Iqbal, M. S. Bhaskar and M. Meraj, "New High Gain 2LC-Y Multilevel-Boost-Converter (2LC-Y MBC) Topologies for Renewable Energy Conversion: Members of X-Y Converter Family," 2019 IEEE 28th International Symposium on Industrial Electronics (ISIE), Vancouver, BC, Canada, 2019, pp. 2647-2652. 